\title{
Determination of the Frumkin and Temkin Adsorption Isotherms of Hydrogen at Nickel/Acidic and Alkaline Aqueous Solution Interfaces Using the Phase-Shift Method and Correlation Constants
}

\author{
Jang H. Chun* \\ Department of Electronic Engineering, Kwangwoon University, Seoul 139-701, Republic of Korea
}

(Received February 16, 2012 : Accepted February 25, 2012)

\begin{abstract}
The phase-shift method and correlation constants, which are unique electrochemical impedance spectroscopy techniques for studying the linear relationship between the phase shift $\left(90^{\circ} \geq-\varphi \geq 0^{\circ}\right)$ vs. potential $(E)$ behavior for the optimum intermediate frequency $\left(f_{o}\right)$ and the fractional surface coverage $(0 \leq \theta \leq 1)$ vs. $E$ behavior, are proposed and verified to determine the Frumkin, Langmuir, and Temkin adsorption isotherms and the related electrode kinetic and thermodynamic parameters. At $\mathrm{Ni} / 0.5 \mathrm{M} \mathrm{H}_{2} \mathrm{SO}_{4}$ and $0.1 \mathrm{M} \mathrm{LiOH}$ aqueous solution interfaces, the Frumkin and Temkin adsorption isotherms $(\theta$ vs. $E)$ of $\mathrm{H}$ for the cathodic hydrogen $\left(\mathrm{H}_{2}\right)$ evolution, interaction parameters $(g)$, equilibrium constants $(K)$, standard Gibbs energies $\left(\Delta G_{\theta}^{o}\right)$ of $\mathrm{H}$ adsorption, and rates of change $(r)$ of $\Delta G_{\theta}^{o}$ with $\theta$ have been determined using the phaseshift method and correlation constants. A lateral repulsive interaction $(g>0)$ between the adsorbed $\mathrm{H}$ species appears. The value of $K$ in the alkaline aqueous solution is much greater than that in the acidic aqueous solution.
\end{abstract}

Keywords : Phase-shift method, Correlation constants, Hydrogen adsorption, Frumkin, Langmuir, Temkin adsorption isotherms, Nickel

\section{Introduction}

Nickel and nickel alloys are the metals most widely used as a cathode for the $\mathrm{H}_{2}$ evolution reaction (HER) in alkaline aqueous solutions. However, there is not much reliable information on the Frumkin adsorption isotherm of $\mathrm{H}$ for the cathodic HER and the related electrode kinetic and thermodynamic parameters of $\mathrm{Ni} /$ acidic and alkaline aqueous solution interfaces. ${ }^{1-7)}$ The determination of the Frumkin adsorption isotherm of $\mathrm{H}$ for the cathodic HER is very difficult using conventional methods. ${ }^{2,7)}$ Therefore, the Langmuir adsorption isotherm has been used to study the adsorption of $\mathrm{H}$ for the cathodic HER at polycrystalline and amorphous $\mathrm{Ni} /$ acidic and alkaline aqueous solution interfaces. ${ }^{5,6)}$ In practice, a polycrystalline and amorphous $\mathrm{Ni}$ implies an inhomogeneous $\mathrm{Ni}$, and so the Frumkin adsorp-

*E-mail: jhchun@kw.ac.kr tion isotherm should be used to study a lateral interaction between adsorbed $\mathrm{H}$ species for the cathodic HER. Correspondingly, the use of the Langmuir adsorption isotherm at $\mathrm{Ni} /$ acidic and alkaline aqueous solution interfaces is basically invalid and incorrect. This is discussed in more detail in the section on the Frumkin, Langmuir, and Temkin adsorption isotherms.

The phase-shift method and correlation constants are unique electrochemical impedance spectroscopy techniques for studying the linear relationship between the phase shift $\left(90^{\circ} \geq-\varphi \geq 0^{\circ}\right)$ vs. potential $(E)$ behavior for the optimum intermediate frequency $\left(f_{o}\right)$ and the fractional surface coverage $(0 \leq$ $\theta \leq 1)$ vs. $E$ behavior of intermediates $(\mathrm{H}, \mathrm{D}, \mathrm{H}+$ $\mathrm{D}, \mathrm{OH}$, etc.) for sequential reactions $\left(\mathrm{H}_{2}, \mathrm{D}_{2}, \mathrm{H}_{2}+\right.$ $\mathrm{D}_{2}, \mathrm{O}_{2}$ evolutions, etc.) at noble and highly corrosion-resistant metal (alloy)/acidic and alkaline normal $\left(\mathrm{H}_{2} \mathrm{O}\right)$ and heavy water $\left(\mathrm{D}_{2} \mathrm{O}\right)$ solution interfaces. ${ }^{8-26)}$ The $\theta$ vs. $E$ behavior of the fractional surface cov- 
erage is well known as the Frumkin or Langmuir adsorption isotherm. ${ }^{1-7)}$

The comments and replies on the phase-shift method are described elsewhere. ${ }^{27-31)}$ The objections to the phase-shift method are substantially attributed to a misunderstanding of the phase-shift method itself. $^{25,26)}$ Note especially that all of the objections to the phase-shift method can be attributed to confusion regarding the applicability of related impedance equations for intermediate frequencies and a unique feature of the Faradaic resistance for the recombination step [1]. The validity and correctness of the phase-shift method should be discussed on the basis of simulations with a single equation for $-\varphi$ vs. $\theta$ as functions of potential and frequency or relevant experimental data which are obtained using other conventional methods. This aspect has never been reported or discussed elsewhere. Because, to the author's knowledge, the interaction parameter and equilibrium constant for the Frumkin adsorption isotherm cannot be determined or estimated using other conventional methods. $^{2,7)}$

In this paper, I present the Frumkin and Temkin adsorption isotherms of $\mathrm{H}$ for the cathodic HER and the related electrode kinetic and thermodynamic parameters of $\mathrm{Ni} / 0.5 \mathrm{M} \mathrm{H}_{2} \mathrm{SO}_{4}$ and $0.1 \mathrm{M} \mathrm{LiOH}$ aqueous solution interfaces using the phase-shift method and correlation constants. These experimental results are useful and effective in understanding the electrode kinetics and mechanism of $\mathrm{H}$ for the cathodic HER at iron group metal and highly corrosion-resistant metal (alloy)/acidic and alkaline aqueous solution interfaces.

\section{Experimental}

\subsection{Preparations}

Taking into account the $\mathrm{H}^{+}$concentration and effects of the diffuse double layer and $\mathrm{pH}^{32)} 0.5 \mathrm{M}$ $\mathrm{H}_{2} \mathrm{SO}_{4}$ and $0.1 \mathrm{M} \mathrm{LiOH}$ aqueous solutions were prepared from $\mathrm{H}_{2} \mathrm{SO}_{4}$ (Sigma-Aldrich, reagent grade) and $\mathrm{LiOH}$ (Alfa Aesar, purity 99.995\%) using purified water $\left(\mathrm{H}_{2} \mathrm{O}\right.$, resistivity $\left.>18 \mathrm{M} \Omega \cdot \mathrm{cm}\right)$ obtained from a Millipore system, respectively. The $\mathrm{pH}$ of the $0.5 \mathrm{M} \mathrm{H}_{2} \mathrm{SO}_{4}$ and $0.1 \mathrm{M} \mathrm{LiOH}$ aqueous solutions were 0.24 and 12.69 , respectively. These solutions were deaerated with $99.999 \%$ purified nitrogen gas for $20 \mathrm{~min}$ before the experiments. A standard three-electrode configuration was employed. A saturated calomel electrode (SCE) was used as the standard reference electrode. A nickel wire (Johnson Matthey, purity 99.999\%, $2 \mathrm{~mm}$ diameter, estimated surface area ca. $1.92 \mathrm{~cm}^{2}$ and $1.98 \mathrm{~cm}^{2}$ ) was used as the working electrode. A platinum wire (Johnson Matthey, purity 99.95\%, $1.5 \mathrm{~mm}$ diameter, estimated surface area ca. $2.26 \mathrm{~cm}^{2}$ ) was used as the counter electrode. The $\mathrm{Ni}$ wire was polished to a mirror finish using $\mathrm{Al}_{2} \mathrm{O}_{3}$ powders $(0.3$ and $0.05 \mu \mathrm{m})$, ultrasonically cleaned in the purified water, and finally rinsed with acetone. The Pt counter electrode was prepared by flame cleaning and then quenched and cooled sequentially in Millipore Milli-Q water and air.

\subsection{Measurements}

A cyclic voltammetry (CV) technique was used to achieve steady states at the $\mathrm{Ni} / 0.5 \mathrm{M} \mathrm{H}_{2} \mathrm{SO}_{4}$ and $0.1 \mathrm{M} \mathrm{LiOH}$ aqueous solution interfaces. The $\mathrm{CV}$ experiments were conducted for 20 cycles at a scan rate of $200 \mathrm{mV} \cdot \mathrm{s}^{-1}$ and a scan potential of (0 to -1.0) V vs. SCE. After the CV experiments, an electrochemical impedance spectroscopy (EIS) technique was used to study the linear relationship between the $-\varphi$ vs. $E$ behavior for $f_{o}$ and the $\theta$ vs. $E$ behavior at the interfaces. The EIS experiments were conducted at scan frequencies $(f)$ of $\left(2 \times 10^{4}\right.$ to 1$) \mathrm{Hz}$ and $\left(10^{4}\right.$ to 0.1$) \mathrm{Hz}$ using a single sine wave, an alternating current (ac) amplitude of $5 \mathrm{mV}$, and a direct current $(\mathrm{dc})$ potential of $(0$ to -1.35$)$ $\mathrm{V}$ vs. SCE.

The CV experiments were performed using an EG\&G PAR Model 273A potentiostat controlled with the PAR Model 270 software package. The EIS experiments were performed using the same apparatus in conjunction with a Schlumberger SI $1255 \mathrm{HF}$ frequency response analyzer controlled with the PAR Model 398 software package. To obtain comparable and reproducible results, all of the measurements were carried out using the same preparations, procedures, and conditions at $298 \mathrm{~K}$. The international sign convention is used: cathodic currents and lagged-phase shifts or angles are taken as negative. All potentials are given on the stan- 
dard hydrogen electrode (SHE) scale. The Gaussian and adsorption isotherm analyses were carried out using the Excel and Origin software packages.

\section{Results and Discussion}

\subsection{Simplified equivalent circuit for the phase-} shift method

The equivalent circuit for the adsorption of $\mathrm{H}$ for the cathodic HER at the $\mathrm{Ni} / 0.5 \mathrm{M} \mathrm{H}_{2} \mathrm{SO}_{4}$ and $0.1 \mathrm{M}$ $\mathrm{LiOH}$ aqueous solution interfaces can be expressed as shown in Fig. 1(a). ${ }^{23-26,33-35)}$ Taking into account the superposition of various effects (relaxation time effects, real surface area problems, surface absorption and diffusion processes, inhomogeneous and lateral interaction effects, oxide layer formation, specific adsorption effects, etc.) that are inevitable under the experimental conditions, we define the equivalent circuit elements as follows: $R_{S}$ is the real solution resistance; $R_{F}$ is the real resistance

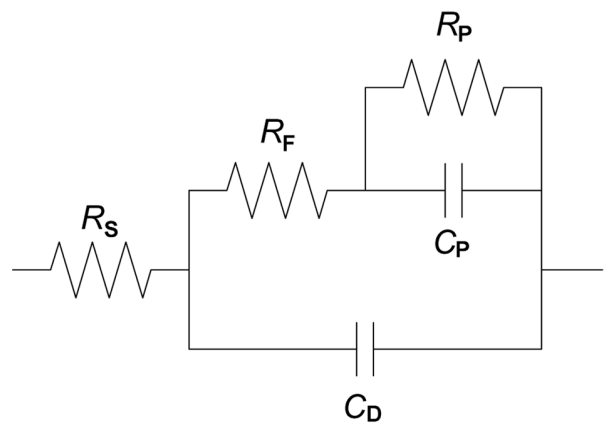

(a)


(b)

Fig. 1. (a) Experimentally proposed equivalent circuit for the phase-shift method. (b) Simplified equivalent circuits for intermediate frequency responses. due to the Faradaic resistance $\left(R_{\phi}\right)$ for the discharge step and superposition of various effects; $R_{P}$ is the real resistance due to the Faradaic resistance $\left(R_{R}\right)$ for the recombination step and superposition of various effects; $C_{P}$ is the real capacitance due to the adsorption pseudocapacitance $\left(C_{\phi}\right)$ for the discharge step and superposition of various effects; and $C_{D}$ is the real double-layer capacitance. Correspondingly, neither $R_{F}$ nor $C_{P}$ is constant; both depend on $E$ and $\theta$ and can be measured. Note that both $R_{\phi}$ and $C_{\phi}$ also depend on $E$ and $\theta$ but cannot be measured.

The frequency responses of the equivalent circuit for all $f$ that is shown in Fig. 1(a) are essential for understanding the unique feature and combination of $\left(R_{S}, R_{F}\right)$ and $\left(C_{P}, C_{D}\right)$ vs. $E$, i.e., the linear relationship between the $-\varphi$ vs. $E$ behavior and the $\theta$ vs. $E$ behavior. At intermediate frequencies, one finds regions in which the equivalent circuit for all $f$ behaves as a series circuit of $R_{S}, R_{F}$, and $C_{P}$ or a series and parallel circuit of $R_{S}, C_{P}$, and $C_{D}$, as shown in Fig. 1(b). However, note that the simplified equivalent circuit shown in Fig. 1(b) does not represent the change of the cathodic HER itself but only the intermediate frequency response.

At intermediate frequencies, the impedance $(Z)$ and lagged phase-shift $(-\varphi)$ are given by ${ }^{25,26)}$

$$
\begin{aligned}
& Z=R_{S}+R_{F}-\frac{j}{\omega C_{P}} \\
& -\varphi=\arctan \left[\frac{1}{\omega\left(R_{S}+R_{F}\right) C_{P}}\right]
\end{aligned}
$$

for the upper circuit in Fig. 1(b) or

$$
\begin{aligned}
& Z=R_{S}-\frac{j}{\omega\left(C_{P}+C_{D}\right)} \\
& -\varphi=\arctan \left[\frac{1}{\omega R_{S}\left(C_{P}+C_{D}\right)}\right]
\end{aligned}
$$

for the lower circuit in Fig. 1(b), where $j$ is the imaginary unit (i.e., $j^{2}=-1$ ) and $\omega$ is the angular frequency, defined as $\omega=2 \pi f$, where $f$ is the frequency. Under these conditions,

$$
R_{P} \gg \frac{1}{\omega C_{p}} \text { and } R_{P} \gg R_{S}+R_{F}
$$

In our previously published papers, ${ }^{8-22)}$ only Eq. (1) was used with a footnote stating that $C_{P}$ practi- 
Table 1. Measured values of the phase shift $(-\varphi)$ for the optimum intermediate frequency $\left(f_{o}=158.9 \mathrm{~Hz}\right)$, the fractional surface coverage $(\theta)$ of hydrogen, and the normalized change rates $[\Delta(-\varphi) / \Delta E, \Delta \theta / \Delta E]$ at the $\mathrm{Ni} / \mathbf{0 . 5}$ $\mathrm{M} \mathrm{H}_{2} \mathrm{SO}_{4}$ aqueous solution interface

\begin{tabular}{ccccc}
\hline$E / \mathrm{V}$ vs. SHE & $-\varphi / \mathrm{deg}$ & $\theta^{a}$ & $\Delta(-\varphi) / \Delta E^{b}$ & $\Delta \theta / \Delta E^{c}$ \\
\hline-0.109 & 82.2 & $\sim 0$ & $\sim 0$ & $\sim 0$ \\
-0.159 & 81.8 & 0.00488 & 0.06341 & 0.06341 \\
-0.209 & 79.1 & 0.03780 & 0.42805 & 0.42805 \\
-0.259 & 71.3 & 0.13293 & 1.23659 & 1.23659 \\
-0.309 & 54.9 & 0.33293 & 2.60000 & 2.60000 \\
-0.359 & 30.8 & 0.62683 & 3.82073 & 3.82073 \\
-0.409 & 13.9 & 0.83293 & 2.67927 & 2.67927 \\
-0.459 & 6.3 & 0.92561 & 1.20488 & 1.20488 \\
-0.509 & 3.1 & 0.96463 & 0.50732 & 0.50732 \\
-0.559 & 1.7 & 0.98171 & 0.22195 & 0.22195 \\
-0.609 & 1.0 & 0.99024 & 0.11098 & 0.11098 \\
-0.659 & 0.5 & 0.99634 & 0.07927 & 0.07927 \\
-0.709 & 0.3 & 0.99878 & 0.03171 & 0.03171 \\
-0.759 & 0.2 & $\sim 1$ & 0.01585 & 0.01585 \\
\hline
\end{tabular}

${ }^{a}$ Estimated using $-\varphi .{ }^{b}\{[$ (neighbor phase shift difference $) /$ (total phase shift difference)]/[(neighbor potential difference)/ (total potential difference) $]\} .{ }^{c}\{[$ (neighbor fractional surface coverage difference)/(total fractional surface coverage difference $)] /[$ (neighbor potential difference)/(total potential difference) $]\}$.

Table 2. Measured values of the phase shift $(-\varphi)$ for the optimum intermediate frequency $\left(f_{o}=5.012 \mathrm{~Hz}\right)$, the fractional surface coverage $(\theta)$ of hydrogen, and the normalized change rates $[\Delta(-\varphi) / \Delta E, \Delta \theta / \Delta E]$ at the $\mathrm{Ni} / 0.1$ $\mathrm{M} \mathrm{LiOH}$ aqueous solution interface

\begin{tabular}{ccccc}
\hline$E / \mathrm{V}$ vs. SHE & $-\varphi / \mathrm{deg}$ & $\theta^{a}$ & $\Delta(-\varphi) / \Delta E^{b}$ & $\Delta \theta / \Delta E^{c}$ \\
\hline-0.459 & 83.4 & $\sim 0$ & $\sim 0$ & $\sim 0$ \\
-0.509 & 83.3 & 0.00120 & 0.01559 & 0.01559 \\
-0.559 & 82.1 & 0.01559 & 0.18705 & 0.18705 \\
-0.609 & 80.5 & 0.03477 & 0.24940 & 0.24940 \\
-0.659 & 78.3 & 0.06115 & 0.34293 & 0.34293 \\
-0.709 & 72.4 & 0.13189 & 0.91966 & 0.91966 \\
-0.759 & 58.5 & 0.29856 & 2.16667 & 2.16667 \\
-0.809 & 41.8 & 0.49880 & 2.60312 & 2.60312 \\
-0.859 & 25.7 & 0.69185 & 2.50959 & 2.50959 \\
-0.909 & 12.9 & 0.84532 & 1.99520 & 1.99520 \\
-0.959 & 4.8 & 0.94245 & 1.26259 & 1.26259 \\
-1.009 & 1.3 & 0.98441 & 0.54556 & 0.54556 \\
-1.059 & 0.2 & 0.99760 & 0.17146 & 0.17146 \\
-1.109 & 0 & $\sim 1$ & 0.03118 & 0.03118 \\
\hline
\end{tabular}

${ }^{a}$ Estimated using $-\varphi .{ }^{b}\{[$ (neighbor phase shift difference $) /$ (total phase shift difference)]/[(neighbor potential difference)/ (total potential difference) $]\} .{ }^{c}\{[$ (neighbor fractional surface coverage difference)/(total fractional surface coverage difference) $] /[($ neighbor potential difference $) /($ total potential difference)]\}. cally includes $C_{D}$ (see Tables 1 and 2 in Ref. 18, Table 1 in Ref. 17, etc.). Both Eqs. (1) and (2) show that the effect of $R_{P}$ on $-\varphi$ for intermediate frequencies is negligible. These aspects are completely overlooked, confused, and misunderstood in the comments on the phase-shift method by HorvatRadosevic, Kvastek, and Lasia. ${ }^{27,29,31)}$ Correspondingly, all of the simulations of the phase-shift method using Eq. (1) that appear in these comments (where $C_{P}$ does not include $\left.C_{D}\right)^{27,29,31)}$ are basically invalid or wrong. ${ }^{25,26)}$ All of the analyses of the effect of $R_{P}$ on $-\varphi$ for intermediate frequencies are also invalid or wrong (see Supporting Information of Refs. 25 and 26). Note that the applicability of Eq. (1) or (2) and the related conditions and limitations are not considered for the phase-shift method because all of the measured values of $-\varphi$ for intermediate frequencies include $\left(R_{S}\right.$, $\left.R_{F}\right)$ and $\left(C_{P}, C_{D}\right)$. Correspondingly, the measured $-\varphi$ for $f_{o}$ is valid and correct regardless of the applicability of Eq. (1) or (2) and the related conditions and limitations. This is the reason why the phaseshift method is useful and effective. The theoretical and experimental backgrounds of the phase-shift method for determining the Frumkin and Langmuir adsorption isotherms of $\mathrm{H}$ for the cathodic HER at the interfaces are described elsewhere. ${ }^{25,26)}$

3.2. Basic procedure and description of the phase-shift method

Figs. 2 and 3 show the phase-shift curves $(-\varphi$ vs. $\log f$ ) for different potentials $(E)$ at the $\mathrm{Ni} / 0.5 \mathrm{M}$ $\mathrm{H}_{2} \mathrm{SO}_{4}$ and $0.1 \mathrm{M} \mathrm{LiOH}$ aqueous solution interfaces, respectively. As shown in Figs. 2 and 3, $-\varphi$ depends on both $f$ and $E$. Correspondingly, the normalized rate of change of $-\varphi$ vs. $E$, i.e., $\Delta(-\varphi) / \Delta E$, depends on both $f$ and $E$. In electrosorption, $\theta$ depends on only $E .^{36)}$ The normalized rate of change of $\theta$ vs. $E$, i.e., $\Delta \theta / \Delta E$, obeys a Gaussian profile. This is a unique feature of the Frumkin and Langmuir adsorption isotherms ( $\theta$ vs. $E$ ).

The intermediate frequencies of $158.9 \mathrm{~Hz}$ and $5.012 \mathrm{~Hz}$, shown as vertical solid lines on the $-\varphi$ vs. $\log f$ plots in Figs. 2 and 3 , can be set as $f_{o}$ for $-\varphi$ vs. $E$ or $\Delta(-\varphi) / \Delta E$ and $\theta$ vs. $E$ or $\Delta \theta / \Delta E$. The determination of $f_{o}$ is experimentally and graphically evaluated on the basis of $\Delta(-\varphi) / \Delta E$ and 


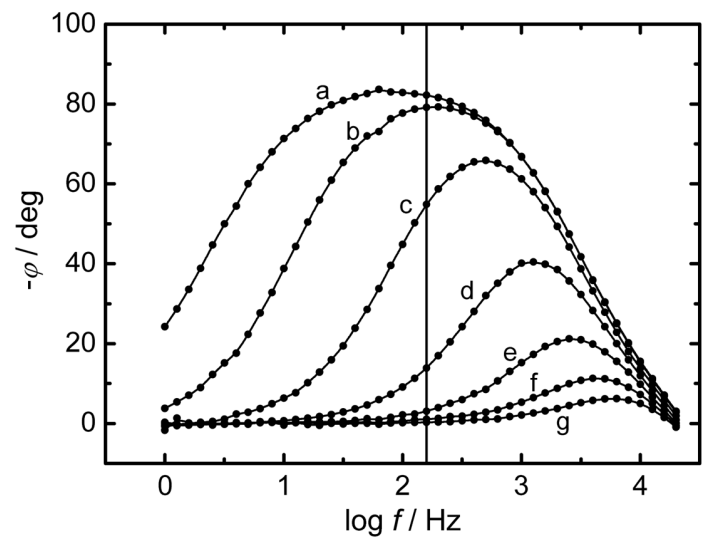

Fig. 2. Comparison of the phase-shift curves $(-\varphi$ vs. $\log f)$ for different potentials $(E)$ at the $\mathrm{Ni} / 0.5 \mathrm{M} \mathrm{H}_{2} \mathrm{SO}_{4}$ aqueous solution interface. Measured values: $\bigcirc$. Vertical solid line: $158.9 \mathrm{~Hz}$; single sine wave; scan frequency range, $\left(2 \times 10^{4}\right.$ to 1$) \mathrm{Hz}$; ac amplitude, $5 \mathrm{mV}$. Dc potentials: (a) $-0.109 \mathrm{~V}$; (b) $-0.209 \mathrm{~V}$; (c) $-0.309 \mathrm{~V}$; (d) $-0.409 \mathrm{~V}$; (e) $-0.509 \mathrm{~V}$; (f) $-0.609 \mathrm{~V}$; (g) $-0.709 \mathrm{~V}$ (all vs. SHE).

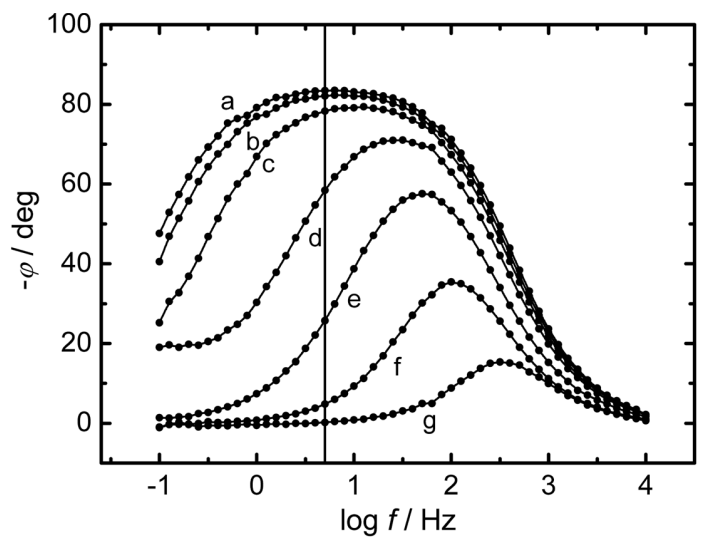

Fig. 3. Comparison of the phase-shift curves $(-\varphi$ vs. $\log f)$ for different potentials $(E)$ at the $\mathrm{Ni} / 0.1 \mathrm{M} \mathrm{LiOH}$ aqueous solution interface. Measured values: $\bigcirc$. Vertical solid line: $5.012 \mathrm{~Hz}$; single sine wave; scan frequency range, $\left(10^{4}\right.$ to 0.1$) \mathrm{Hz}$; ac amplitude, $5 \mathrm{mV}$. De potentials: (a) $-0.459 \mathrm{~V}$; (b) $-0.559 \mathrm{~V}$; (c) $-0.659 \mathrm{~V}$; (d) $-0.759 \mathrm{~V}$; (e) $-0.859 \mathrm{~V}$; (f) $-0.959 \mathrm{~V}$; (g) $-1.059 \mathrm{~V}$ (all vs. SHE).

$\Delta \theta / \Delta E$ for intermediate and other frequencies (see Figs. 6 and 7). The characteristic of the phase-shift method for determining the Frumkin and Langmuir adsorption isotherms is a useful, effective, and experimental technique. If one knows the three points or regions, i.e., the maximum $-\varphi(\theta \approx 0$ and low $E$ region, where $\Delta(-\varphi) / \Delta E$ and $\Delta \theta / \Delta E$ approach
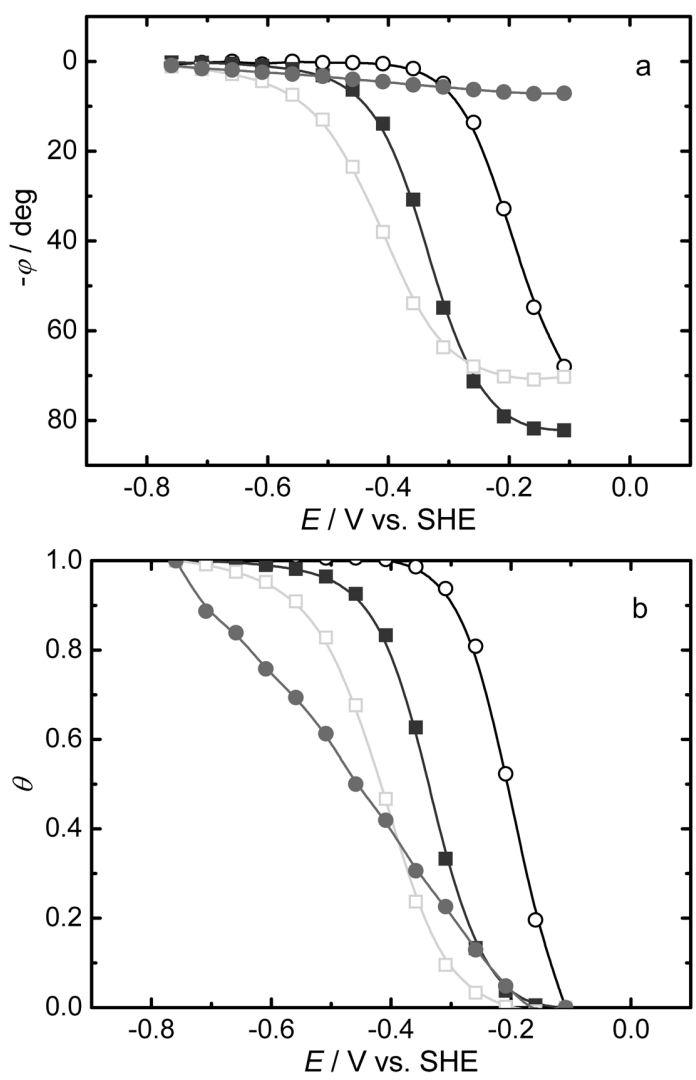

Fig. 4. Comparison of (a) the phase-shift profiles ( $-\varphi$ vs. $E)$ and (b) the fractional surface-coverage profiles $(\theta$ vs. $E$ ) for four different frequencies at the $\mathrm{Ni} / 0.5 \mathrm{M} \mathrm{H}_{2} \mathrm{SO}_{4}$ aqueous solution interface. Measured or estimated values: ○, $7.962 \mathrm{~Hz} ; \square, 158.9 \mathrm{~Hz} ; \square, 796.2 \mathrm{~Hz} ; \bigcirc, 15890 \mathrm{~Hz}$. The optimum intermediate frequency $\left(f_{o}\right)$ is $158.9 \mathrm{~Hz}$.

the minimum value or 0$)$, the medium $-\varphi(\theta \approx 0.5$ and intermediate $E$ region, where $\Delta(-\varphi) / \Delta E$ and $\Delta \theta /$ $\Delta E$ approach the maximum value), and the minimum $-\varphi(\theta \approx 1$ and high $E$ region, where $\Delta(-\varphi) /$ $\Delta E$ and $\Delta \theta / \Delta E$ approach the minimum value or 0 ) for $f_{\mathrm{o}}$, then one can easily determine the object, i.e., the Frumkin or Langmuir adsorption isotherm. In other words, both $\Delta(-\varphi) / \Delta E$ and $\Delta \theta / \Delta E$ for $f_{o}$ are maximized at $\theta \approx 0.5$ and intermediate $E$, decrease symmetrically with $E$ at other values of $\theta$, and are minimized at $\theta \approx 0$ and low $E$ and $\theta \approx 1$ and high $E$. The linear relationship between and Gaussian profiles of $-\varphi$ vs. $E$ or $\Delta(-\varphi) / \Delta E$ and $\theta$ vs. $E$ or $\Delta \theta / \Delta E$ most clearly appear at $f_{o}$ (see Figs. 6(b) and 7(b)). 

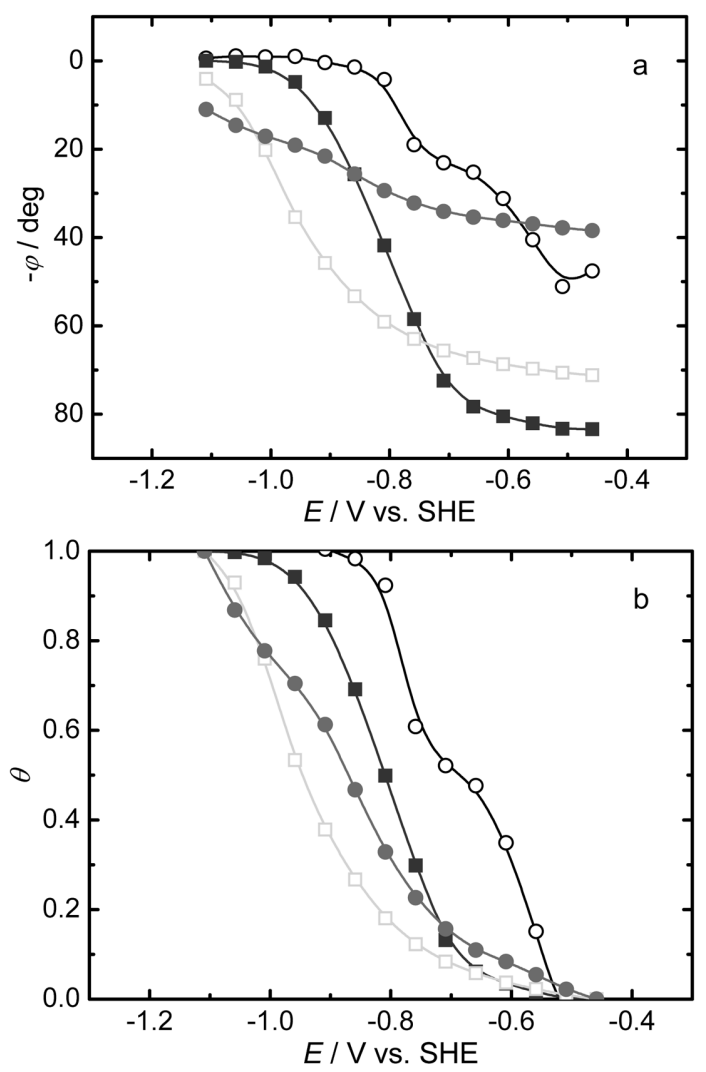

Fig. 5. Comparison of (a) the phase-shift profiles $(-\varphi$ vs. $E)$ and (b) the fractional surface-coverage profiles $(\theta$ vs. $E$ ) for four different frequencies at the $\mathrm{Ni} / 0.1 \mathrm{M} \mathrm{LiOH}$ aqueous solution interface. Measured or estimated values: ○, 0.1 Hz; $\square, 5.012 \mathrm{~Hz} ; \square, 50.12 \mathrm{~Hz} ; 0,501.2 \mathrm{~Hz}$. The optimum intermediate frequency $\left(f_{o}\right)$ is $5.012 \mathrm{~Hz}$.

The procedure and description of the phase-shift method for determining the Frumkin adsorption isotherms of $\mathrm{H}$ for the cathodic HER at the $\mathrm{Ni} / 0.5 \mathrm{M}$ $\mathrm{H}_{2} \mathrm{SO}_{4}$ and $0.1 \mathrm{M} \mathrm{LiOH}$ aqueous solution interfaces are briefly summarized in Tables 1 and 2, respectively. The values of $-\varphi$ and $\theta$ as functions of $E$ at $f_{o}=158.9 \mathrm{~Hz}$ and $5.012 \mathrm{~Hz}$ shown in Figs. 4 and 5 are illustrated on the basis of the experimental results summarized in Tables 1 and 2, respectively. The values of $-\varphi$ and $\theta$ as functions of $E$ at other frequencies shown in Figs. 4 and 5 are also illustrated through the same procedures summarized in Tables 1 and 2, respectively. However, note that the differences between $-\varphi$ vs. $E$ profiles at $f_{o}=158.9 \mathrm{~Hz}$ and $5.012 \mathrm{~Hz}$ and those at other frequencies shown in Figs. 4(a) and 5(a) do not represent the mea- surement error but only the frequency response. In practice, $\theta$ vs. $E$ profiles at other frequencies shown in Figs. 4(b) and 5(b) should be exactly the same as those at $f_{o}=158.9 \mathrm{~Hz}$ and $5.012 \mathrm{~Hz}$, respectively. Because, as stated above, $\theta$ depends on only $E$ and this unique feature most clearly appears at $f_{o}$.

The Gaussian profiles shown in Figs. 6(b) and 7 (b) are illustrated on the basis of $\Delta(-\varphi) / \Delta E$ and $\Delta \theta / \Delta E$ data for $f_{o}=158.9 \mathrm{~Hz}$ and $5.012 \mathrm{~Hz}$ summarized in Tables 1 and 2, respectively. The Gaussian profiles for other frequencies shown in Figs. 6 and 7 were obtained through the same procedures summarized in Tables 1 and 2, respectively. Finally, one can conclude that $\theta$ vs. $E$ profiles at $f_{o}=158.9$ $\mathrm{Hz}$ and $5.012 \mathrm{~Hz}$ shown in Figs. 4(b) and 5(b) are applicable to the determination of the Frumkin adsorption isotherms of $\mathrm{H}$ at the $\mathrm{Ni} / 0.5 \mathrm{M} \mathrm{H}_{2} \mathrm{SO}_{4}$ and $0.1 \mathrm{M} \mathrm{LiOH}$ aqueous solution interfaces, respectively.

\subsection{Frumkin, Langmuir, and Temkin adsorption} isotherms

The derivation and interpretation of the practical forms of the electrochemical Frumkin, Langmuir, and Temkin adsorption isotherms are described elsewhere. ${ }^{37-39)}$ The Frumkin adsorption isotherm assumes that the $\mathrm{Ni}$ surface is inhomogeneous or that the lateral interaction effect is not negligible. The Frumkin adsorption isotherm of $\mathrm{H}$ can be expressed as follows $^{38)}$

$$
\begin{aligned}
& {\left[\frac{\theta}{1-\theta}\right] \exp (g \theta)=K_{o} C^{+} \exp (-E F / R T)} \\
& g=\frac{r}{R T} \\
& K=K_{o} \exp (-g \theta)
\end{aligned}
$$

where $\theta(0 \leq \theta \leq 1)$ is the fractional surface coverage, $g$ is the interaction parameter for the Frumkin adsorption isotherm, $K_{o}$ is the equilibrium constant at $g=0, C^{+}$is the concentration of ions $\left(\mathrm{H}^{+}\right)$in the bulk solution, $E$ is the negative potential, $F$ is Faraday's constant, $R$ is the gas constant, $T$ is the absolute temperature, $r$ is the rate of change of the standard Gibbs energy of $\mathrm{H}$ adsorption with $\theta$, and $K$ is the equilibrium constant. Note that when $g=0$ 

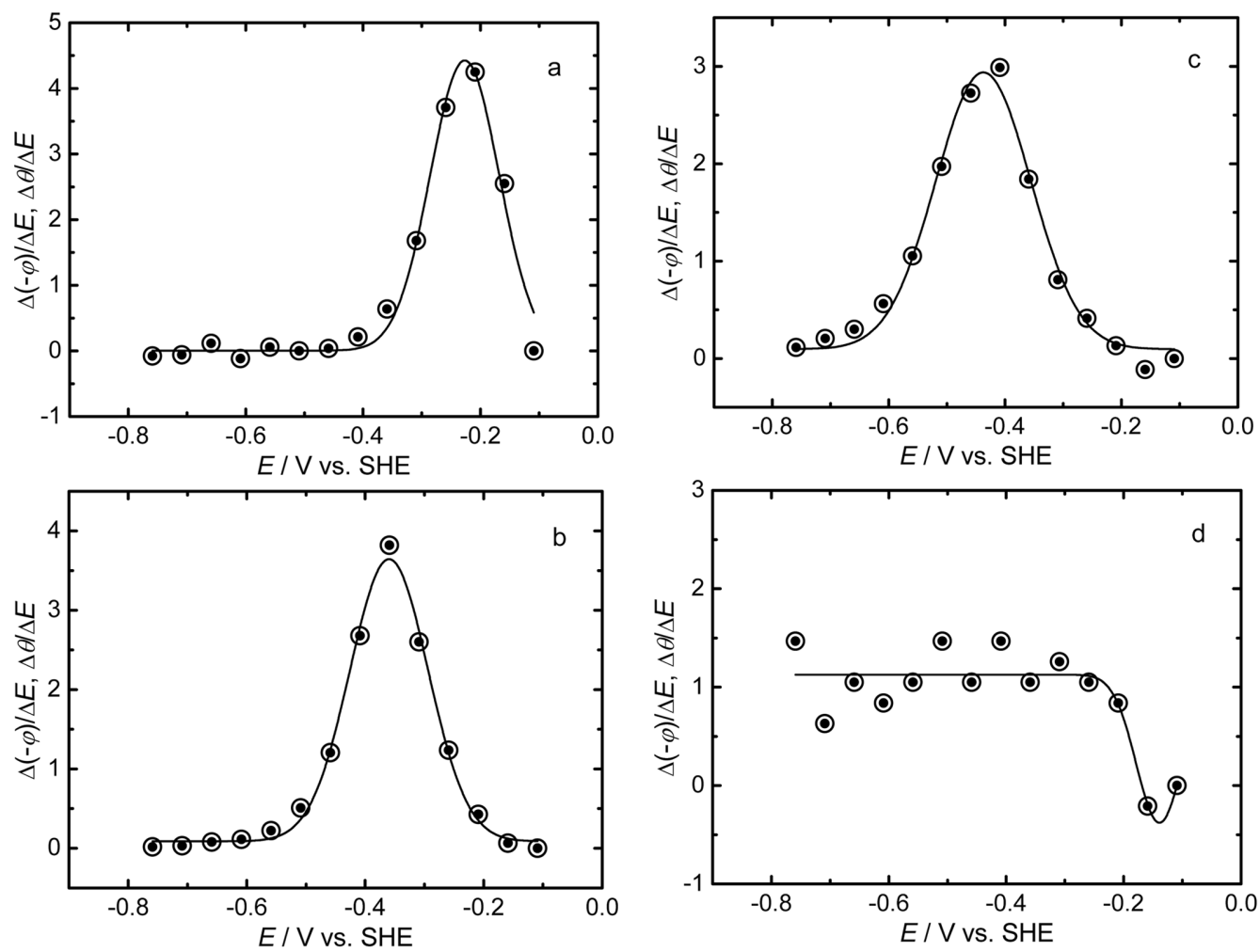

Fig. 6. Comparison of the normalized rates of change of $-\varphi$ and $\theta$ with respect to $E$, i.e., $\Delta(-\varphi) / \Delta E$ and $\Delta \theta / \Delta E$, for four different frequencies at the $\mathrm{Ni} / 0.5 \mathrm{M} \mathrm{H}_{2} \mathrm{SO}_{4}$ aqueous solution interface. - , fitted Gaussian profile; $\bigcirc, \Delta(-\varphi) / \Delta E ; \boldsymbol{O}, \Delta \theta /$ $\Delta E$. (a) $7.962 \mathrm{~Hz}$, (b) $158.9 \mathrm{~Hz}$, (c) $796.2 \mathrm{~Hz}$, and (d) $15890 \mathrm{~Hz}$. The optimum intermediate frequency $\left(f_{o}\right)$ is $158.9 \mathrm{~Hz}$.

in Eqs. (4) to (6), the Langmuir adsorption isotherm is obtained. For the Langmuir adsorption isotherm, when $g=0$, the inhomogeneous and lateral interaction effects on the adsorption of $\mathrm{H}$ are assumed to be negligible.

Thermodynamic equilibrium constants are dimensionless because they are expressed in terms of activities rather than concentrations. The convention in chemical kinetics is to use concentrations rather than activities. Therefore, $K$ described in the Langmuir, Frumkin, and Temkin adsorption isotherms is the empirical equilibrium constant. This constant is not dimensionless and must be multiplied by the concentration of the reference state to be made equal to the thermodynamic equilibrium constants. Nevertheless, to maintain consistency with the conventions of chemical kinetics, such constant as $K$ is referred to as the equilibrium constant in the Langmuir, Frumkin, and Temkin adsorption iso- therms. The dimension of $K$ is described elsewhere. ${ }^{40)}$

At the $\mathrm{Ni} / 0.5 \mathrm{M} \mathrm{H}_{2} \mathrm{SO}_{4}$ and $0.1 \mathrm{M} \mathrm{LiOH}$ aqueous solution interfaces, the numerically calculated Frumkin adsorption isotherms of $\mathrm{H}$ using Eq. (4) are shown in Figs. 8 and 9, respectively. Curves a, $\mathrm{b}$, and $\mathrm{c}$ in Fig. 8 show the three numerically calculated Frumkin adsorption isotherms of $\mathrm{H}$ corresponding to $g=0,5.3$, and 15.3 , respectively, for $K_{o}=4.1 \times 10^{-9} \mathrm{~mol}^{-1}$. Curve b shows that the Frumkin adsorption isotherm, $K=4.1 \times 10^{-9} \exp$ $(-5.3 \theta) \mathrm{mol}^{-1}$, is applicable to the adsorption of $\mathrm{H}$, and Eq. (5) gives $r=13.1 \mathrm{~kJ} \cdot \mathrm{mol}^{-1}$. On the other hand, curves $\mathrm{a}, \mathrm{b}$, and $\mathrm{c}$ in Fig. 9 show the three numerically calculated Frumkin adsorption isotherms of $\mathrm{H}$ corresponding to $g=0,7.4$, and 17.4, respectively, for $K_{o}=3.6 \times 10^{-4} \mathrm{~mol}^{-1}$. Curve b shows that the Frumkin adsorption isotherm, $K=3.6 \times 10^{-4} \exp (-7.4 \theta) \mathrm{mol}^{-1}$, is applicable to the 

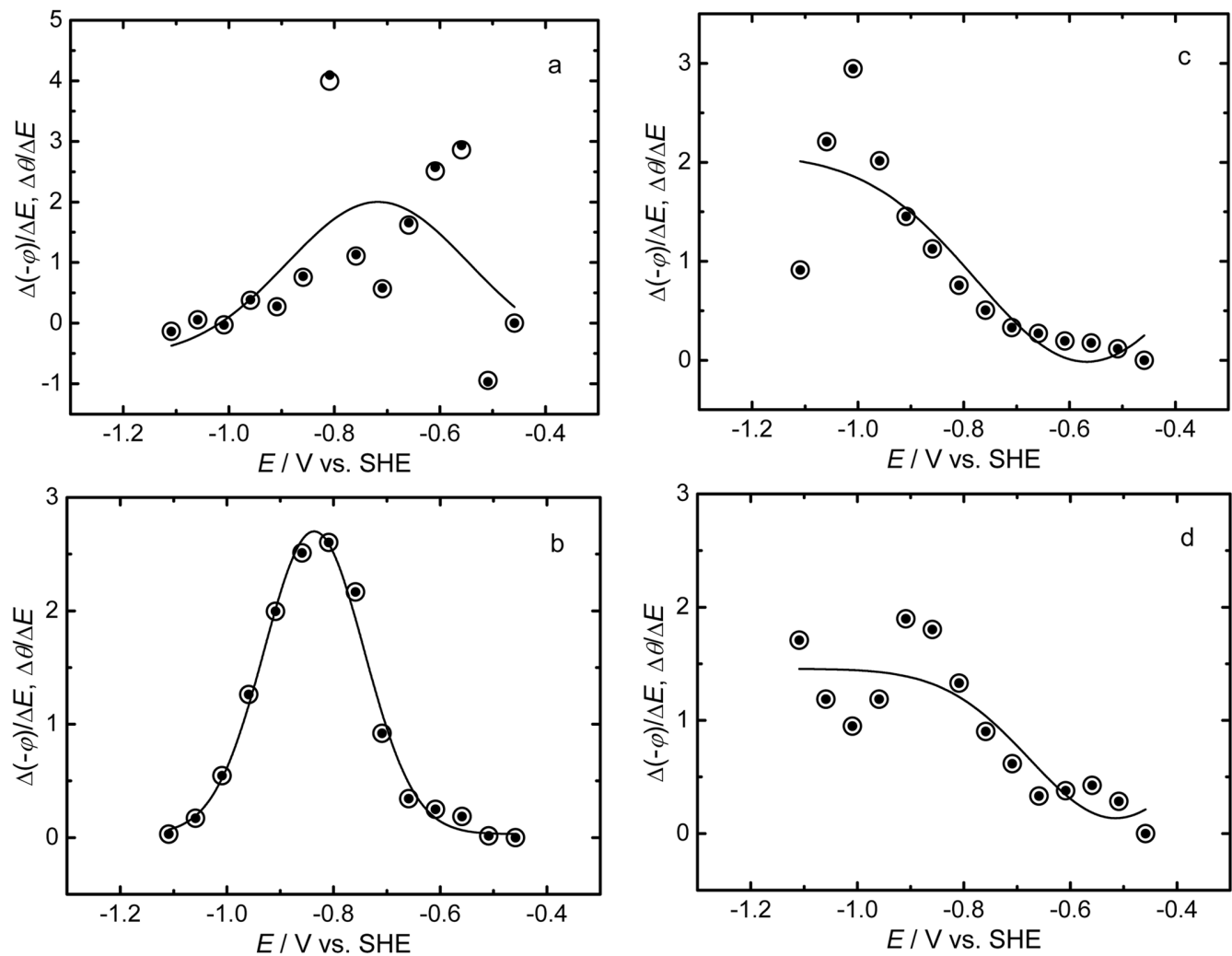

Fig. 7. Comparison of the normalized rates of change of $-\varphi$ and $\theta$ with respect to $E$, i.e., $\Delta(-\varphi) / \Delta E$ and $\Delta \theta / \Delta E$, for four different frequencies at the $\mathrm{Ni} / \mathbf{0 . 1} \mathrm{M} \mathrm{LiOH}$ aqueous solution interface. - , fitted Gaussian profile; $\bigcirc, \Delta(-\varphi) / \Delta E ; \boldsymbol{O}, \Delta \theta /$ $\Delta E$. (a) $0.1 \mathrm{~Hz}$, (b) $5.012 \mathrm{~Hz}$, (c) $50.12 \mathrm{~Hz}$, and (d) $501.2 \mathrm{~Hz}$. The optimum intermediate frequency $\left(f_{o}\right)$ is $5.012 \mathrm{~Hz}$.

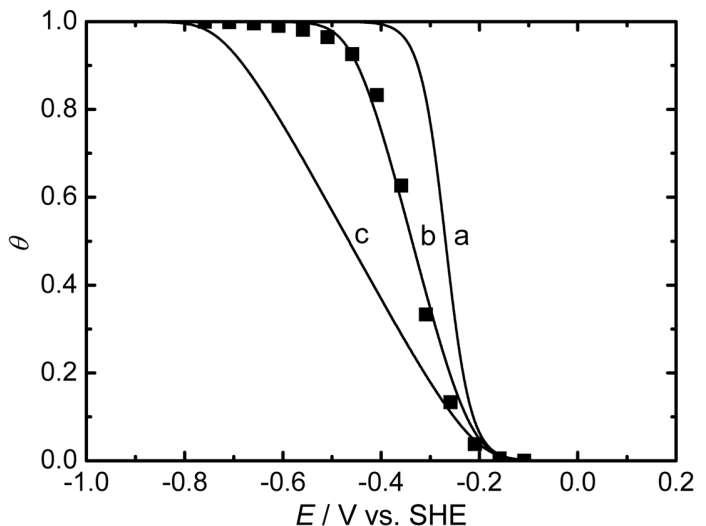

Fig. 8. Comparison of the experimental and fitted data for the Frumkin adsorption isotherms $(\theta$ vs. $E)$ of $\mathrm{H}$ at the $\mathrm{Ni} /$ $0.5 \mathrm{M} \mathrm{H}_{2} \mathrm{SO}_{4}$ aqueous solution interface. Experimental data: $\square$. Solid curves show values calculated using Eq. (4) (the Frumkin adsorption isotherm) for (a) $g=0$, (b) $g=5.3$, and (c) $g=15.3$ with $K_{o}=4.1 \times 10^{-9} \mathrm{~mol}^{-1}$. The Frumkin adsorption isotherm shown in curve $b$ of Fig. 8 is $K=4.1 \times 10^{-9} \exp (-5.3 \theta) \mathrm{mol}^{-1}$.

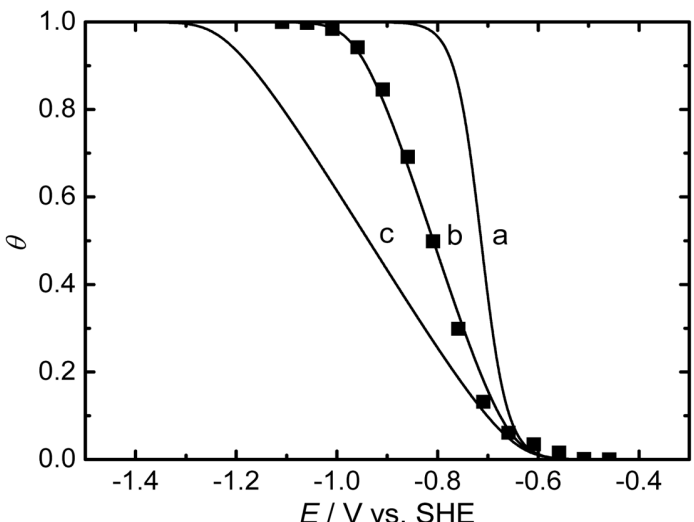

Fig. 9. Comparison of the experimental and fitted data for the Frumkin adsorption isotherms $(\theta$ vs. $E)$ of $\mathrm{H}$ at the $\mathrm{Ni} /$ 0.1 M LiOH aqueous solution interface. Experimental data: $\square$. Solid curves show values calculated using Eq. (4) (the Frumkin adsorption isotherm) for (a) $g=0$, (b) $g=7.4$, and (c) $g=17.4$ with $K_{o}=3.6 \times 10^{-4} \mathrm{~mol}^{-1}$. The Frumkin adsorption isotherm shown in curve $b$ of Fig. 9 is $K=3.6 \times 10^{-4} \exp (-7.4 \theta) \mathrm{mol}^{-1}$. 


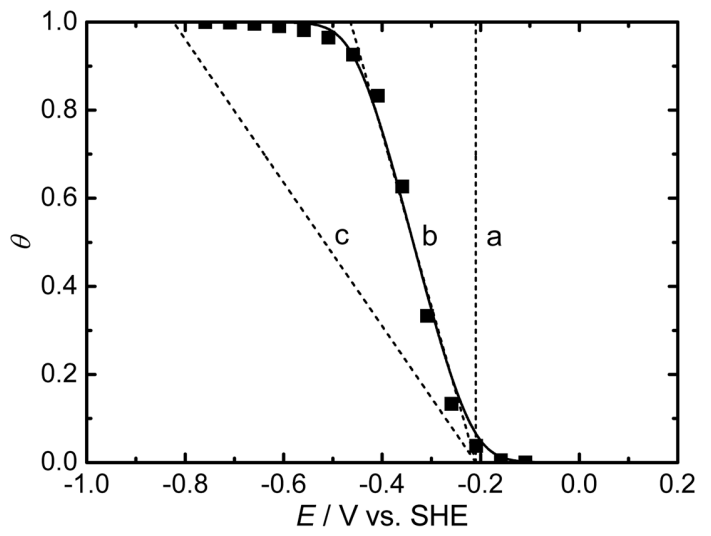

Fig. 10. Comparison of the experimentally determined Frumkin adsorption isotherm and three fitted Temkin adsorption isotherms $(\theta$ vs. $E)$ of $\mathrm{H}$ at the $\mathrm{Ni} / 0.5 \mathrm{M} \mathrm{H}_{2} \mathrm{SO}_{4}$ aqueous solution interface. Experimental data: $\square$. The solid curve shows the Frumkin adsorption isotherm calculated using Eq. (4). Dashed lines show values calculated using Eq. (7) (the Temkin adsorption isotherm) and the correlation constants for (a) $g=0$, (b) $g=9.9$, and (c) $g=23.9$ with $K_{o}=4.1 \times 10^{-8} \mathrm{~mol}^{-1}$. The Temkin adsorption isotherm shown in dashed line $b$ of Fig. 10, $K=4.1 \times 10^{-8} \exp (-9.9 \theta) \mathrm{mol}^{-1}$, is valid and effective only for $0.2<\theta<0.8$.

adsorption of $\mathrm{H}$, and Eq. (5) gives $r=18.4 \mathrm{~kJ}$. $\mathrm{mol}^{-1}$.

At intermediate values of $\theta$ (i.e., $0.2<\theta<0.8$ ), the pre-exponential term, $[\theta /(1-\theta)]$, varies little with $\theta$ in comparison with the variation of the exponential term, $\exp (g \theta)$ (see Eq. (4)). Under these approximate conditions, the Temkin adsorption isotherm can be simply derived from the Frumkin adsorption isotherm. The Temkin adsorption isotherm of $\mathrm{H}$ can be expressed as follows ${ }^{38)}$

$$
\exp (g \theta)=K_{o} C^{+} \exp (-E F / R T)
$$

Figs. 10 and 11 show the determination of the Temkin adsorption isotherms corresponding to the Frumkin adsorption isotherms shown in curves b of Figs. 8 and 9, respectively. The dashed line labeled $\mathrm{b}$ in Fig. 10 shows that the numerically calculated Temkin adsorption isotherm of $\mathrm{H}$ using Eq. (7) is $K=4.1 \times 10^{-8} \exp (-9.9 \theta) \mathrm{mol}^{-1}$, and Eq. (5) gives $r=24.6 \mathrm{~kJ} \cdot \mathrm{mol}^{-1}$. On the other hand, the dashed line labeled $\mathrm{b}$ in Fig. 11 shows that the numerically calculated Temkin adsorption isotherm of $\mathrm{H}$ using Eq. (7) is $K=3.6 \times 10^{-3} \exp (-12 \theta) \mathrm{mol}^{-1}$, and

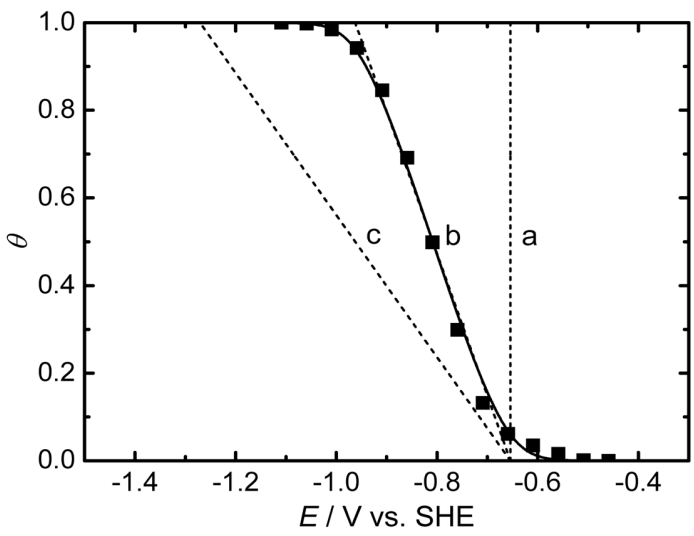

Fig. 11. Comparison of the experimentally determined Frumkin adsorption isotherm and three fitted Temkin adsorption isotherms $(\theta$ vs. $E)$ of $\mathrm{H}$ at the $\mathrm{Ni} / 0.1 \mathrm{M} \mathrm{LiOH}$ aqueous solution interface. Experimental data: $\square$. The solid curve shows the Frumkin adsorption isotherm calculated using Eq. (4). Dashed lines show values calculated using Eq. (7) (the Temkin adsorption isotherm) and the correlation constants for (a) $g=0$, (b) $g=12$, and (c) $g=24$ with $K_{o}=3.6 \times 10^{-3} \mathrm{~mol}^{-1}$. The Temkin adsorption isotherm shown in dashed line b of Fig. 11, $K=3.6 \times 10^{-3} \exp (-12 \theta) \mathrm{mol}^{-1}$, is valid and effective only for $0.2<\theta<0.8$.

Eq. (5) gives $r=29.8 \mathrm{~kJ} \cdot \mathrm{mol}^{-1}$. Note that the Temkin adsorption isotherms of $\mathrm{H}$ represented by the dashed lines $\mathrm{b}$ in Figs. 10 and 11 are valid and effective only for $0.2<\theta<0.8$.

\subsection{Correlation constants between the adsorption} isotherms

For $0.2<\theta<0.8$, all of the Langmuir adsorption isotherms are always parallel to each other. ${ }^{38)}$ Correspondingly, all of the slopes of the Langmuir adsorption isotherms, i.e., all of $g$ for the Temkin adsorption isotherms, are all the same. We have experimentally and consistently found and confirmed that $g$ for the Temkin adsorption isotherms are approximately 4.6 greater than those for the Langmuir adsorption isotherms. Similarly, $g$ for the Temkin adsorption isotherms are approximately 4.6 greater than those for the Frumkin adsorption isotherms (see Table 3). Because the Frumkin adsorption isotherms are determined on the basis of the Langmuir adsorption isotherms, i.e., $g=0$ (see Figs. 8 and 9). In addition, we have experimentally and consistently found and confirmed that the equilib- 
Table 3. Comparison of the interaction parameters $(g)$ and equilibrium constants $(K)$ for the Frumkin and Temkin adsorption isotherms of $\mathbf{H}$, the standard Gibbs energies $\left(\Delta \boldsymbol{G}_{\theta}^{o}\right)$ of $\mathbf{H}$ adsorption, and the rates of change $(r)$ of $\Delta G_{\theta}^{o}$ with $\theta$ at the $\mathrm{Ni} / 0.5 \mathrm{M} \mathrm{H}_{2} \mathrm{SO}_{4}$ and $0.1 \mathrm{M} \mathrm{LiOH}$ aqueous solution interfaces

\begin{tabular}{lccccc}
\hline Solution & Adsorption isotherm & $g$ & $K / \mathrm{mol}^{-1}$ & $\Delta G_{\theta}^{o} / \mathrm{kJ} \cdot \mathrm{mol}^{-1}$ & $r / \mathrm{kJ} \cdot \mathrm{mol}^{-1}$ \\
\hline $0.5 \mathrm{M} \mathrm{H}_{2} \mathrm{SO}_{4}$ & Frumkin $^{a}$ & 5.3 & $4.1 \times 10^{-9} \exp (-5.3 \theta)$ & $47.8 \leq \Delta G_{\theta}^{o} \leq 61.0$ & 13.1 \\
$0.5 \mathrm{M} \mathrm{H}_{2} \mathrm{SO}_{4}$ & Temkin $^{b}$ & 9.9 & $4.1 \times 10^{-8} \exp (-9.9 \theta)$ & $47.0<\Delta G_{\theta}^{o}<61.7$ & 24.6 \\
$0.1 \mathrm{M} \mathrm{LiOH}$ & Frumkin $^{a}$ & 7.4 & $3.6 \times 10^{-4} \exp (-7.4 \theta)$ & $19.6 \leq \Delta G_{\theta}^{o} \leq 38.0$ & 18.4 \\
$0.1 \mathrm{M} \mathrm{LiOH}$ & Temkin $^{b}$ & 12.0 & $3.6 \times 10^{-3} \exp (-12 \theta)$ & $19.9<\Delta G_{\theta}^{o}<37.8$ & 29.8 \\
\hline
\end{tabular}

${ }^{a}$ Frumkin adsorption isotherm is valid and effective at $0 \leq \theta \leq 1 .{ }^{b}$ Temkin adsorption isotherm is valid and effective only at $0.2<\theta<0.8$.

rium constants $\left(K_{o}\right)$ for the Temkin adsorption isotherms are approximately 10 times greater than those $\left(K_{o}\right.$ or $\left.K\right)$ for the correlated Frumkin or Langmuir adsorption isotherms (see Figs. 10 and 11). These aspects are described elsewhere. . $^{17,18,21-26)}$

In this work, one can also confirm that the values of $g$ and $K_{o}$ for the Temkin adsorption isotherms are approximately 4.6 and 10 times greater than those for the correlated Frumkin or Langmuir adsorption isotherms, respectively. The Temkin adsorption isotherms correlating with the Frumkin or Langmuir adsorption isotherms, and vice versa, are readily determined using the correlation constants. Note that this is a unique feature between the Temkin and Frumkin or Langmuir adsorption isotherms.

\subsection{Standard Gibbs energy of adsorption}

Under the Frumkin adsorption conditions, the relationship between the equilibrium constant $(K)$ for $\mathrm{H}$ and the standard Gibbs energy $\left(\Delta G_{\theta}^{o}\right)$ of $\mathrm{H}$ adsorption is ${ }^{38)}$

$$
2.3 R T \log K=-\Delta G_{\theta}^{\mathrm{o}}
$$

For the $\mathrm{Ni} / 0.5 \mathrm{M} \mathrm{H}_{2} \mathrm{SO}_{4}$ aqueous solution interface, use of Eqs. (6) and (8) shows that $\Delta G_{\theta}^{o}$ is in the range $\left(47.8 \leq \Delta G_{\theta}^{o} \leq 61.0\right) \mathrm{kJ} \cdot \mathrm{mol}^{-1}$ for $K=4.1 \times$ $10^{-9} \exp (-5.3 \theta) \mathrm{mol}^{-1}$ and $0 \leq \theta \leq 1$. This result implies a decrease of $\left|\Delta G_{\theta}^{o}\right|$ with $\theta(0 \leq \theta \leq 1)$. Note that $\Delta G_{\theta}^{o}$ is a negative number, i.e., $\Delta G_{\theta}^{o}<0$. The interaction parameters $(g)$ and equilibrium constants $(K)$ for the Frumkin and Temkin adsorption isotherms, the standard Gibbs energies $\left(\Delta G_{\theta}^{o}\right)$ of $\mathrm{H}$ adsorption, and the rates of change $(r)$ of $\Delta G_{\theta}^{o}$ with $\theta$ at the $\mathrm{Ni} / 0.5 \mathrm{M} \mathrm{H}_{2} \mathrm{SO}_{4}$ and $0.1 \mathrm{M} \mathrm{LiOH}$ aqueous solution interfaces are summarized in Table 3.

\section{Conclusions}

At the $\mathrm{Ni} / 0.5 \mathrm{M} \mathrm{H}_{2} \mathrm{SO}_{4}$ and $0.1 \mathrm{M} \mathrm{LiOH}$ aqueous solution interfaces, the Frumkin and Temkin adsorption isotherms ( $\theta$ vs. $E$ ) of $\mathrm{H}$, the interaction parameters $(g)$, the equilibrium constants $(K)$, the standard Gibbs energies $\left(\Delta G_{\theta}^{o}\right)$ of $\mathrm{H}$ adsorption, and the rates of change $(r)$ of $\Delta G_{\theta}^{o}$ of $\mathrm{H}$ adsorption with $\theta$ are determined using the phase-shift method and correlation constants. The value of $K$ for the Frumkin adsorption isotherm of $\mathrm{H}, K=3.6 \times 10^{-4}$ $\exp (-7.4 \theta)$, in $0.1 \mathrm{M} \mathrm{LiOH}$ aqueous solution is much greater than that, $K=4.1 \times 10^{-9} \exp (-5.3 \theta)$, in $0.5 \mathrm{M} \mathrm{H}_{2} \mathrm{SO}_{4}$ aqueous solution.

The Frumkin adsorption isotherms should be used to determine the electrode kinetic and thermodynamic parameters of the $\mathrm{Ni} / 0.5 \mathrm{M} \mathrm{H}_{2} \mathrm{SO}_{4}$ and $0.1 \mathrm{M}$ $\mathrm{LiOH}$ aqueous solution interfaces. The lateral repulsive interaction $(g>0)$ between the adsorbed $\mathrm{H}$ species appears. The lateral interaction effect, i.e., $g$ and $r$, is not negligible. The values of $K$ in alkaline aqueous solutions are much greater than those in acidic aqueous solutions.

The phase-shift method and correlation constants are the most accurate and reliable ways to determine the Frumkin, Langmuir, and Temkin adsorption isotherms and related electrode kinetic and thermodynamic parameters of the interfaces. They are useful and effective in facilitating selection of the optimal electrode material to yield an electrochemical system of maximum hydrogen evolution performances.

\section{Acknowledgement}

This work was supported by the Research Grant 
of Kwangwoon University in 2011.

\section{Symbols and Acronyms}

$C^{+}$: concentration of ions in the bulk solution

$C_{D}$ : real double-layer capacitance

$C_{P}$ : real capacitance due to $C_{\phi}$ and superposition of various effects

$\mathrm{CV}$ : cyclic voltammetry

$C_{\phi}$ : adsorption pseudocapacitance for the discharge step

D : adsorbed deuterium atom

$E$ : potential

EIS : electrochemical impedance spectroscopy

$F$ : Faraday's constant

$f:$ frequency

$f_{o}$ : optimum intermediate frequency

$\Delta G_{\theta}^{o}$ : standard Gibbs energy of adsorption

$g:$ interaction parameter

$\mathrm{H}$ : adsorbed hydrogen atom

HER : hydrogen evolution reaction

$j$ : imaginary unit

$K$ : equilibrium constant

$K_{o}$ : equilibrium constant at $g=0$

$R$ : gas constant

$R_{F}$ : real resistance due to $R_{\phi}$ and superposition of various effects

$R_{P}$ : real resistance due to $R_{R}$ and superposition of various effects

$R_{R}$ : Faradaic resistance for the recombination step

$R_{S}$ : real solution resistance

$R_{\phi}$ : Faradaic resistance for the discharge step

$r$ : rate of change of the standard Gibbs energy of adsorption with $\theta$

SCE : saturated calomel electrode

SHE : standard hydrogen electrode

$T:$ absolute temperature

$Z$ : impedance

$\Delta \theta / \Delta E$ : normalized rate of change of $\theta$ vs. $E$

$\Delta(-\varphi) / \Delta E$ : normalized rate of change of $-\varphi$ vs. $E$

$\theta$ : fractional surface coverage $(0 \leq \theta \leq 1)$

$-\varphi$ : lagged phase-shift or phase-angle $\left(90^{\circ} \geq-\varphi\right.$ $\left.\geq 0^{\circ}\right)$

$\omega$ : angular frequency

\section{Footnote}

[1] In our e-mail communications, Horvat-
Radosevic and Kvastek admitted that all of their objections to the phase-shift method in Ref. 31 were confused and misunderstood. The exact same confusion and misunderstanding about the phaseshift method also appear in Refs. 27 and 29.

\section{References}

1. E. Gileadi, "Electrode kinetics", VCH, New York (1993).

2. B. E. Conway, G. Jerkiewicz (Eds.), "Electrochemistry and materials science of cathodic hydrogen absorption and adsorption" Electrochemical Society Proceedings, Vol. 94-21, The Electrochemical Society, Pennington, NJ (1995).

3. G. Jerkiewicz, P. Marcus (Eds.), 'Electrochemical surface science and hydrogen adsorption and absorption' Electrochemical Society Proceedings, Vol. 97-16, The Electrochemical Society, Pennington, NJ (1997).

4. G. Jerkiewicz, J. M. Feliu, and B. N. Popov (Eds.), "Hydrogen at surface and interfaces", Electrochemical Society Proceedings, Vol. 2000-16, The Electrochemical Society, Pennington, NJ (2000).

5. N. Krstajic, M. Popovic, B. Grgur, M. Vojnovic, and D. Sepa, 'On the kinetics of the hydrogen evolution reaction on nickel in alkaline solution. Part I. The mechanism' $J$. Electroanal. Chem., 512, 16 (2001).

6. H. E. Alami, J. Creus, and X. Feaugas, 'Thermodynamic parameters evolution versus plastic strain during HER on nickel in sulphuric acid' Electrochim. Acta, 52, 4004 (2007).

7. G. Jerkiewicz, 'Electrochemical hydrogen adsorption and absorption. Part 1: Under-potential deposition of hydrogen' Electrocatal., 1, 179 (2010).

8. J. H. Chun and K. H. Ra, 'The phase-shift method for the Frumkin adsorption isotherms at the $\mathrm{Pd} / \mathrm{H}_{2} \mathrm{SO}_{4}$ and $\mathrm{KOH}$ solution interfaces' J. Electrochem. Soc., 145, 3794 (1998).

9. J. H. Chun, K. H. Ra, and N. Y. Kim, 'The Langmuir adsorption isotherms of electroadsorbed hydrogens for the cathodic hydrogen evolution reactions at the $\mathrm{Pt}(100) /$ $\mathrm{H}_{2} \mathrm{SO}_{4}$ and $\mathrm{LiOH}$ aqueous electrolyte interfaces' Int. $J$. Hydrogen Energy, 26, 941 (2001).

10. J. H. Chun, K. H. Ra, and N. Y. Kim, 'Qualitative analysis of the Frumkin adsorption isotherm of the overpotentially deposited hydrogen at the poly-Ni/KOH aqueous electrolyte interface using the phase-shift method' J. Electrochem. Soc., 149, E325 (2002).

11. J. H. Chun, K. H. Ra, and N. Y. Kim, 'Langmuir adsorption isotherms of over-potentially deposited hydrogen at poly-Au and $\mathrm{Rh} / \mathrm{H}_{2} \mathrm{SO}_{4}$ aqueous electrolyte interfaces; Qualitative analysis using the phase-shift method' J. Electrochem. Soc., 150, E207 (2003).

12. J. H. Chun, 'Methods for estimating adsorption isotherms in electrochemical systems' U.S. Patent, 6613218 (2003). 
13. J. H. Chun, S. K. Jeon, B. K. Kim, and J. Y. Chun, 'Determination of the Langmuir adsorption isotherms of under- and over-potentially deposited hydrogen for the cathodic $\mathrm{H}_{2}$ evolution reaction at poly-Ir/aqueous electrolyte interfaces using the phase-shift method' Int. J. Hydrogen Energy, 30, 247 (2005).

14. J. H. Chun, S. K. Jeon, K. H. Ra, and J. Y. Chun, 'The phase-shift method for determining Langmuir adsorption isotherms of over-potentially deposited hydrogen for the cathodic $\mathrm{H}_{2}$ evolution reaction at poly-Re/aqueous electrolyte interfaces' Int. J. Hydrogen Energy, 30, 485 (2005).

15. J. H. Chun, S. K. Jeon, N. Y. Kim, and J. Y. Chun, 'The phase-shift method for determining Langmuir and Temkin adsorption isotherms of over-potentially deposited hydrogen for the cathodic $\mathrm{H}_{2}$ evolution reaction at the poly- $\mathrm{Pt} / \mathrm{H}_{2} \mathrm{SO}_{4}$ aqueous electrolyte interface' Int. $J$. Hydrogen Energy, 30, 1423 (2005).

16. J. H. Chun and N. Y. Kim, 'The phase-shift method for determining adsorption isotherms of hydrogen in electrochemical systems' Int. J. Hydrogen Energy, 31, 277 (2006).

17. J. H. Chun, S. K. Jeon, and J. Y. Chun, 'The phase-shift method and correlation constants for determining adsorption isotherms of hydrogen at a palladium electrode interface' Int. J. Hydrogen Energy, 32, 1982 (2007).

18. J. H. Chun, N. Y. Kim, and J. Y. Chun, 'Determination of adsorption isotherms of hydrogen and hydroxide at PtIr alloy electrode interfaces using the phase-shift method and correlation constants' Int. J. Hydrogen Energy, 33, 762 (2008).

19. J. Y. Chun and J. H. Chun, 'Correction and supplement to the determination of the optimum intermediate frequency for the phase-shift method [Chun et al., Int. J. Hydrogen Energy 30 (2005) 247-259, 1423-1436]' Int. J. Hydrogen Energy, 33, 4962 (2008).

20. J. Y. Chun and J. H. Chun, 'A negative value of the interaction parameter for over-potentially deposited hydrogen at Pt, Ir, and PtIr alloy electrode interfaces' Electrochem. Commun., 11, 744 (2009).

21. J. Y. Chun and J. H. Chun, 'Determination of adsorption isotherms of hydrogen on titanium in sulfuric acid solution using the phase-shift method and correlation constants' J. Chem. Eng. Data, 54, 1236 (2009).

22. J. H. Chun and J. Y. Chun, 'Determination of adsorption isotherms of hydrogen on zirconium in sulfuric acid solution using the phase-shift method and correlation constants' J. Korean Electrochem. Soc., 12, 26 (2009).

23. J. Chun, J. Lee, and J. H. Chun, 'Determination of adsorption isotherms of over-potentially deposited hydrogen on platinum and iridium in $\mathrm{KOH}$ aqueous solution using the phase-shift method and correlation constants' $J$. Chem. Eng. Data, 55, 2363 (2010).

24. J. Chun, N. Y. Kim, and J. H. Chun, 'Determination of adsorption isotherms of hydroxide and deuteroxide on PtIr alloy in LiOH solutions using the phase-shift method and correlation constants' J. Chem. Eng. Data, 55, 3825 (2010).

25. J. Chun, N. Y. Kim, and J. H. Chun, 'Determination of the adsorption isotherms of hydrogen and deuterium isotopes on a PtIr alloy in $\mathrm{LiOH}$ solutions using the phase-shift method and correlation constants' J. Chem. Eng. Data, 55, 5598 (2010).

26. J. Chun, N. Y. Kim, and J. H. Chun, 'Determination of the adsorption isotherms of overpotentially deposited hydrogen on a PtIr alloy in $\mathrm{H}_{2} \mathrm{SO}_{4}$ aqueous solution using the phase-shift method and correlation constants' $J$. Chem. Eng. Data, 56, 251 (2011).

27. K. Kvastek and V. Horvat-Radosevic, 'Comment on: "Langmuir adsorption isotherms of over-potentially deposited hydrogen at poly- $\mathrm{Au}$ and $\mathrm{Rh} / \mathrm{H}_{2} \mathrm{SO}_{4}$ aqueous electrolyte interfaces; Qualitative analysis using the phase-shift method, J. Electrochem. Soc., 150 (2003) E207-217"' J. Electrochem. Soc., 151, L9 (2004).

28. J. H. Chun, K. H. Ra, and N. Y. Kim, 'Response to comment on: "Langmuir adsorption isotherms of overpotentially deposited hydrogen at poly-Au and $\mathrm{Rh} / \mathrm{H}_{2} \mathrm{SO}_{4}$ aqueous electrolyte interfaces; Qualitative analysis using the phase-shift method, J. Electrochem. Soc. 150 (2003) E207-217"' J. Electrochem. Soc., 151, L11 (2004).

29. A. Lasia, "Comments on: "The phase-shift method for determining Langmuir adsorption isotherms of overpotentially deposited hydrogen for the cathodic $\mathrm{H}_{2}$ evolution reaction at poly-Re/aqueous electrolyte interfaces, Int. J. Hydrogen Energy 30 (2005) 485-499"' Int. J. Hydrogen Energy, 30, 913 (2005).

30. J. H. Chun, S. K. Jeon, N. Y. Kim, and J. Y. Chun, 'Response to comments on: "The phase-shift method for determining Langmuir adsorption isotherms of overpotentially deposited hydrogen for the cathodic $\mathrm{H}_{2}$ evolution reaction at poly-Re/aqueous electrolyte interfaces, Int. J. Hydrogen Energy 30 (2005) 485-499"' Int. J. Hydrogen Energy, 30, 919 (2005).

31. V. Horvat-Radosevic and K. Kvastek, 'Pitfalls of the phase-shift method for determining adsorption isotherms' Electrochem. Commun., 11, 1460 (2009).

32. E. Gileadi, E. Kirowa-Eisner, and J. Penciner, 'Interfacial electrochemistry' Addison-Wesley, Reading, MA, 6, 7273 (1975).

33. E. Gileadi, E. Kirowa-Eisner, and J. Penciner, 'Interfacial electrochemistry', Addison-Wesley, Reading, MA, 86-93 (1975).

34. D. A. Harrington, and B. E. Conway, 'AC impedance of faradaic reactions involving electrosorbed intermediates-I. Kinetic theory', Electrochim. Acta, 32, 1703 (1987).

35. E. Gileadi, "Electrode kinetics", VCH, New York, 291303 (1993).

36. E. Gileadi, "Electrode kinetics", VCH, New York, 1993, 307-309 (1993).

37. E. Gileadi, E. Kirowa-Eisner, and J. Penciner, 'Interfacial electrochemistry', Addison-Wesley, Reading, MA, 82-86 (1975). 
38. E. Gileadi, "Electrode kinetics", VCH, New York, 261280 (1993).

39. JO'M. Bockris, A. K. N. Reddy, and M. Gamboa-Aldeco, "Modern electrochemistry", 2nd Ed., Kluwer Academic/
Plenum Press, New York, Vol. 2A, 1193-1197 (2000).

40. D. W. Oxtoby, H. P. Gillis, and N. H. Nachtrieb, "Principles of modern chemistry", 5th Ed., Thomson Learning Inc., New York, 446 (2002). 